\title{
Techniques for the measurement of the Poggendorff and Zoellner illusions in large-group situations
}

\author{
STANLEY COREN \\ University of British Columbia, Vancouver, British Columbia V6T IW5, Canada \\ and \\ CLARE PORAC \\ University of Victoria, Victoria, British Columbia V8W 2Y2, Canada
}

\begin{abstract}
Although validated procedures exist for group measurement of illusions of extent and area, few exist for the measurement of illusions of direction and orientation. Two new groupmeasurement techniques, for the Poggendorff and Zoellner illusions, are presented. These are shown to be sensitive enough to detect the usually obtained parametric variations of illusion magnitude with specific changes in stimulus configurations.
\end{abstract}

Over the past several years, we have conducted a number of investigations into the role of individual difference variables in the susceptibility to visualgeometric illusions (Coren, Girgus, Ehrlichman, \& Hakstian, 1976; Coren \& Porac, 1978a, 1978b; Coren \& Ward, in press; Porac, Coren, Girgus, \& Verde, in press; Coren \& Porac, Note 1; Coren, Porac, Green, \& Dawson, Note 2). All of these studies have used large samples of observers, either to obtain stable individual difference estimates or because the problems of interest involved the application of multivariate analytic procedures. The technique of illusion measurement used in the previous studies involved either reproducing an illusory extent or matching an illusion test extent to one of a graded series of comparison stimuli. Both of these procedures have been shown to provide valid measurements of illusion magnitude, and both can be modified for testing observers in large groups (Coren \& Girgus, 1972a). These two methods have been shown to be most useful when applied to illusions of length, such as the Mueller-Lyer, or illusions of size, such as the Titchner's circles or Ebbinghaus illusion. They are often difficult to use when dealing with illusions of direction or orientation. The purpose of this paper is to present a group testing procedure for the measurement of two orientation distortions, the Poggendorff and the Zoellner illusions, and to show that this new method of illusion measurement provides data that are similar to those obtained with more traditional techniques.

This research was supported in part by grants from the Natural Sciences and Engineering Research Council of Canada and the Medical Research Council of Canada. Carol Behman, Kathy Cooper, Lorna McCrea, Ron Musa, Janet Nicholby, Foley Penrose, and Candace Taylor assisted in scoring and administration. This research represents the shared and equal contributions of both authors.

\section{EXPERIMENT 1}

The first experiment was conducted to validate a group-measurement technique for the Poggendorff illusion. Figure 1A shows the standard form of the Poggendorff, where the transversal marked $X$ appears as if it will pass beneath the transversal marked $Y$. Pressey and Sweeney (1970) modified this figure by removing transversal $Y$; they then demonstrated that illusion magnitude can be measured by asking observers to mentally extrapolate transversal $\mathrm{X}$ until it intersects the vertical. Figure 1B illustrates a variant of the Poggendorff, based upon a similar procedure, that was designed for group measurement of the illusion. In this configuration, the observer's task is to imagine that the oblique line can be extended until it intersects with one of the letters in the column to the right of the vertical line.

It is well known that the magnitude of the Poggendorff distortion varies as a function of the angle between the transversal and the vertical line elements. The illusion is maximal when the angle is acute and disappears when the transversal forms a 90-deg angle with the vertical (for reviews, see Coren \& Girgus, 1978; Weintraub \& Krantz, 1971). We, therefore, decided to assess the sensitivity of the group-measurement procedure by parametrically varying the angle of the transversal and observing whether the expected changes in illusion magnitude were obtained.

\section{Method}

Stimuli. The Poggendorff configuration shown as Figure 1B was printed in black on white paper. The vertical line was $16 \mathrm{~cm}$ and the transversals $3 \mathrm{~cm}$. There were four angles at which the transversal intersected the vertical line; they were $30,45,60$, and 


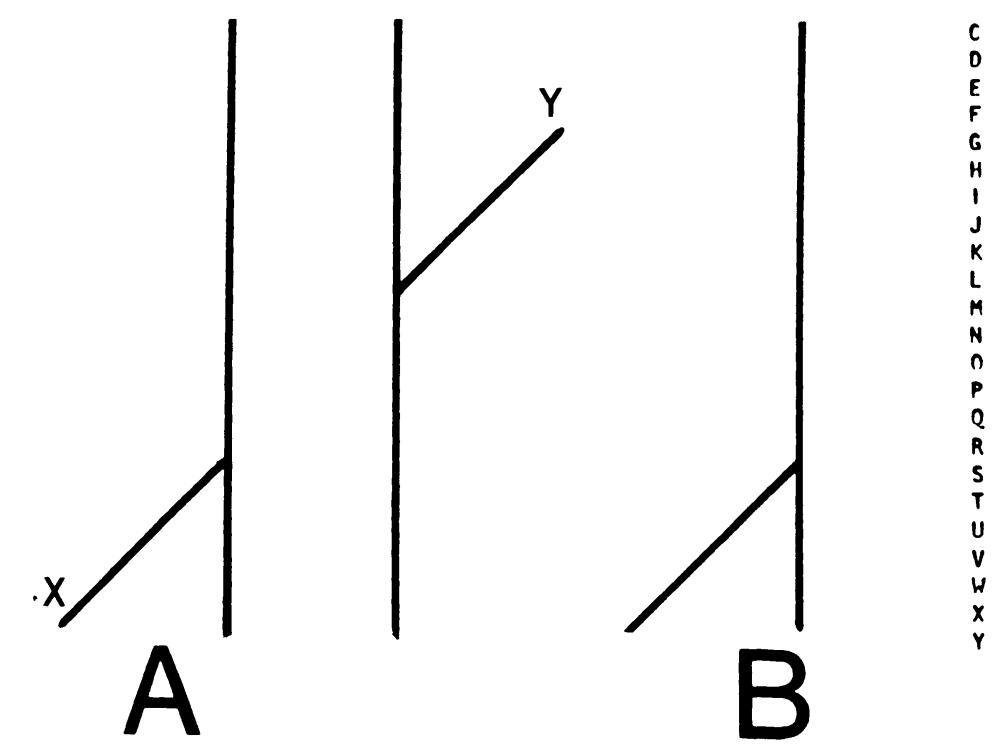

Figure 1. (A) The standard Poggendorff illusion. (B) The Poggendorff illusion modified for group measurement.

$90 \mathrm{deg}$. The column of letters was $5 \mathrm{~cm}$ to the right of the vertical line and each letter measured $2 \mathrm{~mm}$.

Procedure. Eighty female undergraduate volunteers, naive to the purpose of the experiment, served as observers. They were tested as a group in a large auditorium. Task instructions were given on the test form and repeated verbally. Observers were instructed to keep their stimulus pages flat on their tables and to estimate, by eye, the letters that each of the four transversals would cross if extended. Each observer judged all four transversal orientations, and care was taken to insure that the participants completed the task quickly and without the aid of any artificial measuring devices, such as rulers.

\section{Results}

Figure 2 shows the results plotted in millimeters of illusion. As can be seen from the figure, the expected systematic variation in illusion magnitude as a function of transversal angle was obtained. There was a steady decrease in the distortion as the intersection angle increased to $90 \mathrm{deg}$. This observed decrease is statistically significant $[F(3,237)=66.51, p<.001]$.

On the basis of the existing literature, the expectation was that the 90-deg transversal-vertical intersection would result in no illusory distortion, while each of the other stimulus angles would produce significant levels of illusion magnitude. This was the pattern of results obtained. The 90-deg intersection is not significantly different from $0(z=1.75)$, while all of the other angle variations produced highly significant levels of illusion magnitude $(z=10.22,12.03$, and 10.43 , respectively; $p<.001$ ). The degree of consistency between the expected results (derived from more traditional testing procedures) and those obtained here indicate that this group-measurement technique is valid and reliable enough to be used when large numbers of individuals are to be assessed on the Poggendorff illusion.

\section{EXPERIMENT 2}

This experiment presents a group-measurement technique for the Zoellner illusion, which is based upon similar principles. Figure 3 shows two variants of the Zoellner array, the herringbone version (Figure 3A) and the exploded version (Figure 3B). In both, the physically parallel vertical lines seem to diverge as they move upward. The exploded form has been shown to produce a weaker illusory effect than that produced by the herringbone variant (for reviews, see Coren \& Girgus, 1978; Robinson, 1972). In the group-measurement technique, the observer estimates which of the letters in the horizontal row above the figure would be intersected by each vertical line if the lines were extended upward.

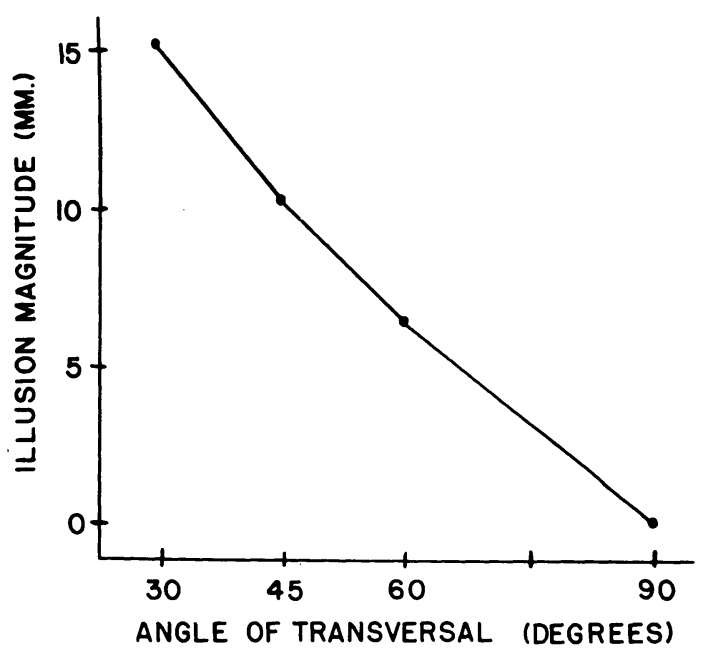

Figure 2. Variation in the magnitude of the Poggendorff illusion as a function of transversal angle as measured via the group illusion measurement technique. 


\section{ABCDEFGHI JKLMMOPQRSTUV}

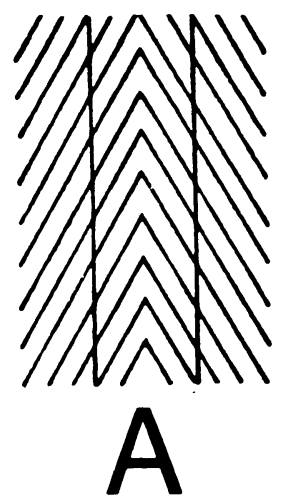

ABCDEFGHIJKLMWOPQNSTUVHXYY

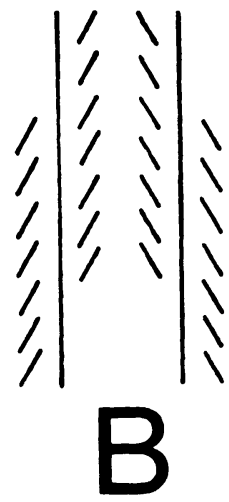

Figure 3. (A) The herringbone variant and (B) the exploded variant of the Zoellner illusion. Both are presented in a form for group measurement.

The apparent divergence of the two lines (and hence, the illusion magnitude) can be computed from this information. Using the same reasoning as for the Poggendorff illusion, we would expect the group technique to both detect the presence of the illusion and detect differences in illusion magnitude resulting from variations in the configuration.

\section{Method}

Stimuli. The two variants of the Zoellner illusion shown in Figure 3 were used. In the herringbone version (Figure 3A), the angle of the inducing lines was $60 \mathrm{deg}$ from the horizontal and the parallel vertical lines were separated by $16 \mathrm{~mm}$. In the exploded form (Figure 3B), the angles of the inducing lines were also $60 \mathrm{deg}$ from the horizontal, with a $5-\mathrm{mm}$ gap between the vertical test lines and the oblique inducing elements. The horizontal row of letters was $5 \mathrm{~cm}$ above each illusion figure and the letters measured $2 \mathrm{~mm}$ in width.

Procedure. Eighty female undergraduate volunteers, naive to the purpose of the experiment, participated as observers. The administration procedure was identical to that described in Experiment 1 except that the observers were asked to indicate the letters that the vertical lines would cross if extended (in imagination) toward the top of the page. Each observer judged both configurations.

\section{Results}

The herringbone variant produced an illusion magnitude of $4.95 \mathrm{~mm}$, while the magnitude obtained with the exploded form was $3.48 \mathrm{~mm}$. Both of these values are significantly greater than zero $(z=15.01$ and 12.17 , respectively; $p<.001)$. In line with our prior expectations, the herringbone form of the illusion produced a significantly greater illusory effect than the exploded form $[F(1,79)=33.87, p<.001]$. The groupmeasurement technique thus provides data on illusion magnitude in the Zoellner illusion that are comparable to those obtained with other experimental procedures.

\section{DISCUSSION}

These experiments show that the Poggendorff and the Zoellner illusions can be measured using a procedure that is suitable for large-group testing situations. The standard illusory distortions can be detected using these procedures, and variations in illusion magnitude due to parametric changes in illusion conformation can also be measured.

These illusion measurement techniques have a number of distinct advantages. For example, no equipment, other than the stimulus itself and a pencil, is required. Observers seem able to comprehend the task and make their judgments quickly and confidently. Also, scoring is unambiguous, since one need only encode the letter selected by the observer. It seems likely that these procedures could be modified for direct machine scoring of the responses. Since rapid and accurate assessment of illusion magnitude in large groups of observers is possible with these procedures, one can obtain stable estimates of central tendency without requiring each observer to repeat the illusion measurement several times. Thus the potential influence of decrement in illusion magnitude, as a result of continued exposure to the illusion configuration, can be reduced (Coren \& Girgus, 1972b; Coren \& Hoenig, 1972). The major limitation on the sensitivity of this method seems to be the size of the letters used in the array. An illusion magnitude that is smaller than the diameter of a single letter (in the present instance, $2 \mathrm{~mm}$ ) cannot be measured. However, reductions in letter size or increases in the distance between the illusion stimulus and the row of measurement letters (to expand the scale of an angular distortion) can be employed.

It seems likely that these group procedures for the measurement of illusions may have wide applicability. It may even be possible to extend the general principle involved in these measurement procedures (namely, the imaginary extension of a line until it intersects an array of markers) to allow group measurement of other illusions of direction or orientation.

\section{REFERENCE NOTES}

1. Coren, S., \& Porac, C. Genetic components in visual illusions. Paper presented at the annual meeting of the Psychonomic Society, Saint Louis, November 1976.

2. Coren, S., Porac, C., Green, S., \& Dawson, I. The MuellerLyer illusion from age 8 to age 80 . Paper presented at the annual meeting of the Psychonomic Society, Washington, D.C., November 1977.

\section{REFERENCES}

Coren, S., \& Girgus, J. S. A comparison of five methods of illusion measurement. Behavior Research Methods \& Instrumentation, 1972, 4, 240-244. (a)

Coren, S., \& Girgus, J. S. Illusion decrement in intersecting line figures. Psychonomic Science, 1972, 26, 108-110. (b)

Coren, S., \& Girgus, J. S. Seeing is deceiving: The psychology of visual illusions. Hillsdale, N.J: Erlbaum, 1978.

Coren, S., Girgus, J. S., Ehrlichman, H., \& Hakstian, A. R. An empirical taxonomy of visual illusions. Perception \& Psychophysics, 1976, 20, 129-137.

Coren, S., \& Hoenig, P. Eye movements and decrement in the Oppel-Kundt illusion. Perception \& Psychophysics, 1972, 12, 224-225.

Coren, S., \& Porac, C. Iris pigmentation and visual-geometric illusions. Perception, 1978, 7, 473-478. (a)

Coren, S., \& Porac, C. A new analysis of life-span age trends in visual illusions. Developmental Psychology, 1978, 14, 193-194. (b)

COREN, S., \& WARD, L. M. Levels of processing in visual illusions: The combination and interaction of distortion-producing mechanisms. Journal of Experimental Psychology: Human Perception and Performance, in press.

Porac. C., Coren, S.. Girgus, J. S., \& Verde. D. Visualgeometric illusions: Uni-sexed phenomena. Perception, in press. 
Pressey, A. W., \& Sweeney, O. Age trends in the Poggendorff illusion as measured by a method of deduction. Psychonomic Science, 1970, 19, 99-100.

RoBinson, J. O. The psychology of visual illusion. London: Hutchinson, 1972.
Weintraub, D. J., \& Krantz, D. H. The Poggendorff illusion: Amputations, rotations, and other perturbations. Perception \& Psychophysics, 1971, 10, 257-264.

(Received for publication January 16, 1979.) 